\title{
The Effect of Parenting Styles on Strengths of Humanity: Love, Kindness and Social Intelligence in Myanmar Adolescents
}

\author{
Thae $\mathrm{Su} \mathrm{Mo}$ \\ School of Psychology, Northeast Normal University \\ 5268 Renmin Street, Changchun 130024, China
}

\begin{abstract}
The main purpose of this study was to explore the effect of parenting styles on strengths of humanity (love, kindness and social intelligence) in Myanmar adolescents. 378 students from three selected secondary schools participated in this study. The Scale of Parenting Styles developed by Gafoor and Kurkkan (2014) was used to measure parental responsiveness and control, for identifying parenting styles. Strengths of humanity were measured through 96-item Value in Action Inventory designed by Park and Peterson (2006). The results showed that adolescents perceived their mothers as more responsive and more controlling than their father. Perceptions with parental responsiveness and control were not different between boys and girls. Maternal responsiveness positively predicted strengths of love and kindness, while paternal control positively predicted social intelligence. Adolescents of authoritative mothers had higher scores in all humanity strengths than those of negligent mothers, and higher scores of kindness than those of permissive mothers. Similarly, adolescents of authoritative fathers reported higher scores in all humanity strengths than those of negligent fathers, and higher scores of kindness than those of permissive fathers. Adolescents of negligent mothers also revealed lower level of love than those of permissive mothers, while adolescents of negligent fathers revealed lower level of love than those of authoritarian fathers. In social intelligence, adolescents of negligent fathers were lower than their counterparts of parents who practiced other three styles. Adolescents of permissive and authoritarian styles did not show significant differences in all three strengths of humanity. On the whole, authoritative parenting style was the best, and negligent style was the worst.
\end{abstract}

Keywords: Parenting Style, Character Strengths, Strengths of Humanity, Love, Kindness, Social Intelligence, Myanmar

DOI: $10.7176 /$ RHSS/9-8-05

Publication date: April $30^{\text {th }} 2019$

\section{Introduction}

Parenting have long been studied and discussed in social psychological field, and many scholars (e.g., Champney, 1941; Schaefer, 1959; Baumrind, 1968; Rohner, 1976; Buri, 1991; Sessa, Avenevoli, Steinberg, \& Morris, 2001) introduced different aspects of parenting which were labelled as parenting practices or factor or dimension or styles. Based on the previous findings and discussions, many theoretical frameworks have been developed and refined to grab the holistic nature of parenting. For example, in the article "The measurement of parent behaviour", Champney (1941) introduced the three parenting behaviours - democracy in the home, acceptance of child and indulgence. Then, Baldwin (1955) identified nine aspects of parenting behaviours - warmth, possessiveness, democracy, intellectuality, restrictiveness, severity, interference, adjustment and activeness. Trying to conceptualize parenting based on the parenting behaviour of democracy and acceptance, many researchers proposed new frameworks (e.g., Lorr \& Jenkins, 1953; Slater, 1962; Roe \& Siegelman, 1963). In 1968, Baumrind proposed three parenting styles: Authoritarian, Authoritative and Permissive. Following her work, Maccoby and Martin (1983) suggested an additional parenting style "Negligent" and these four parenting styles became popular in parenting studies. They posited that two dimensions of parenting - responsiveness and demandingness (control) - decide these four parenting styles. Authoritative parenting style is composed of high responsiveness and high control; authoritarian parenting style, with low responsiveness and high control; permissive parenting style, with high responsiveness and low control; and indulgent parenting, with low responsiveness and low control. According to Baumrind (1991), the best way of parenting children is balanced nurturance (responsiveness) and limit-setting (control) which can be found in authoritative parenting styles.

As this classification of parenting style was exact and systematic, many studies used this framework and proved that authoritative parenting was the best parenting style delivering positive outcomes to children. In reviewing the consequences of parenting styles found by Baumrind (1991), Weiss and Schwarz (1996), and Miller, Cowan, Cowan and Hetherington (1993), Darling (1999) concluded that children and adolescents of authoritative parents were more socially and instrumentally competent than their counterparts of non-authoritative parents, together with low behaviour problems. Specifically, children and adolescents of authoritarian families were lower in social skills and self-esteem, and revealed higher levels of depression; those of permissive families demonstrated more involvement in problematic behaviour and lower performance in school: those of negligent homes showed 
the poorest performance in all domains of competence.

However, some studies found that authoritative parenting was not related to the school grades of Asian Americans (Dornbusch, Ritter, Leiderman, Roberts, \& Fraleigh, 1987), and Hong Kong Chinese (Leung, Lau, \& Lam, 1998; McBride-Chang, \& Chang, 1998). In the study of "Parenting Styles of Hmong Parents and its Effects and Contributions to Hmong Student's Academic Achievement", Moua (2010) found that although Hmong parents were more authoritarian type, the school performance of their children was better than Caucasian students of authoritative parents. Moua argued that "Diana Baumrind's parenting styles may not necessarily reflect those of other ethnic cultures" (p.3). In her study of "consequences of parenting style for Chinese Americans and European Americans", Chao (2001) found that school performance of Chinese youths whose parents were authoritative were not better than Chinese youths of authoritarian families, whereas the school performance of European youths who belonged to authoritative parents was better than European youths of authoritarian parents. And she suggested the researchers, practitioners and educators not to treat authoritative parenting as a prototype for some Asian American groups. Chao and Tseng (2002) contended that the merit of this parenting style could reflect only Western groups, excluding Asian groups. However, the point of paradox for consequences of authoritative parenting is usually situated in the area of academic performance. Steinberg, Dornbusch and Brown (1992) proved that adolescents of authoritative parents had better psychosocial development which reflected self-reliance, work orientation, selfesteem, and personal and social competence; less psychological distress including anxiety, depression, and psychosomatic complaints; and less behaviour problems including drug and alcohol use, delinquency, susceptibility to antisocial peer pressure, and school misconduct, in all ethnic groups-White-American, AsianAmerican, African-American and Hispanic-American.

Questioning the benefit of authoritative parenting in a non-Western setting, the present study intended to investigate, in Myanmar, the relationship between parenting styles and strengths of humanity which was a core virtue of character strengths and not related to school performance. Character strengths are a family of morally positively valued traits which are reflected in thoughts, feelings and behaviours, and related to several positive outcomes (Park, 2004; Ruch, Martínez-Martí, Proyer, \& Harzer, 2014). In their handbook for character strengths published in 2004, Peterson and Seligman introduced 24 strengths grouped under six universal virtues: (1) wisdom and knowledge, (2) courage, (3) humanity, (4) justice, (5) temperance, and (6) transcendence. In page 29 and 30 of the handbook, Peterson and Seligman (2004) gave explanation for the meaning and composition of the six virtues. Wisdom and knowledge characterize cognitive strengths which give rise to knowledge pursuit and applying knowledge into human affairs, consisting of five strengths: creativity, curiosity, critical thinking, love of learning and perspective. Courage represents emotional strengths which comprise the exercise of will for accomplishing goals against external or internal opposition, and includes four strengths: bravery, persistence, integrity and zest. For the virtue of humanity, the composition of three strengths - love, kindness and social intelligence - reflects interpersonal strengths of caring others and fostering familiarity. As virtue of justice, three strengths - teamwork, fairness and leadership - portray civic strengths of favouring equity within society. The virtue of temperance is comprised of four strengths - forgiveness, modesty, prudence and self-regulation — which facilitate controlling over excess. The last virtue, transcendence, consists of appreciation of beauty and excellence, gratitude, hope, humour and religiousness, representing the strengths which provide people with meaning of living through the connections to the larger universe (or something higher such as God).

Research on character strengths has already proved that 24 character strengths had a number of important links to positive outcomes (e.g., academic achievement, life satisfaction, and well-being) in children and youth (Park, 2009; Niemiec, 2013). In the study of Wagner and Ruch (2015), nine character strengths including social intelligence showed positive correlations with classroom behaviour and school achievement. High social intelligence as a strength of humanity lets an individual aware of not only the mind of others but also himself. This benefits people to possess smoother social functioning (Peterson \& Seligman, 2004). Another strength of humanity, kindness, is what we all expect from everyone in the world. Kindness, also viewed as altruism, is the primary motive behind volunteerism which benefits every society (Peterson \& Seligman, 2004). The last strength "love", representing the capacity to love and be loved, helps a person in forging secure attachment, trust and intimacy (Peterson \& Seligman, 2004). Typically, these three strengths "love, kindness and social intelligence" are highly related to the social aspect of life, bringing positive relations with others and making a person more humane, as they were grouped under the virtue of humanity.

In the development of good characters which bring in the positive life outcomes to everyone, many factors make contribution. For example, good parenting, family and peer intimacy, positive role models, positive institutions, and youth development programs have important impact on the development of character strengths (Park, 2004). Investigating the effect of parental boding on eight character strengths of adolescents in Hong Kong, Ngai (2015) found the positive effect of parental care and the negative effect of parental control on the three strengths of humanity, integrity, bravery, persistence, fairness and self-regulation. According to Darling (1999), parental care (responsiveness) is related with social competence and higher psychological functioning, while parental control (demandingness) predicts instrumental competence — academic performance — and behavioural 
control-less involvement in problematic behaviour. Although the parental responsiveness result of Ngai (2015) was in line with the proposition of Darling (1999), contradiction was found in the negative effect of parental control on character strengths. Moreover, Ngai (2015) did not investigate the combined effect of parental care and parental control, i.e., as parenting styles.

The present study replicated the work of Ngai (2015) with a focus on strengths of humanity and in different setting, proposing the following hypotheses:

(1) Parental responsiveness will have significant positive effect on strengths of humanity.

(2) Parental control will have significant negative effect on strengths of humanity.

(3) The strengths of humanity will be higher in the children of authoritative parents than those of nonauthoritative parents.

\section{Methodology}

A survey was conducted to 378 adolescents in three secondary schools under the permission of respective principals. 134 males comprised $35.4 \%$ and 244 females comprised $64.6 \%$ of the sample population. The age of participants ranged from 12 to 17 and the mean age was 13.76. Two questionnaires: Scale of Parenting Styles (see Appendix) and 96-item Value in Action Inventory were used to measure parenting styles and the strengths of humanity.

Scale of Parenting Styles (SOPS) was developed by Gafoor and Kurukkan (2014), recommending the high relevance of scales for south Asian adolescents. The scale measures adolescents' perception of parental responsiveness and parental control. 19 items - $1,2,4,6,8,10,12,14,16,18,20,22,24,26,28,30,32,34$ and 36-represents parental responsiveness; 19 items - 3, 5, 7, 9, 11, 13, 15, 17, 19, 21, 23, 25, 27, 29, 31, 33, 35, 37 and 38 -represents parental control. The rating format applied is 5-point Likert Scale: $1=$ very wrong, $2=$ mostly wrong, 3 = sometimes right, sometimes wrong, $4=$ mostly right and $5=$ very right. Gafoor and Kurukkan (2014) instructed to categorize high or low parental responsiveness and control using median-split method first and then to identify parenting styles according to high or low level of the two dimensions. 96-items Value in Action Inventory (VIA Youth-96) was developed by Park and Peterson (2006). The inventory consists of 96 items (4 items per each strength), measuring 24 character strengths through 5-point Likert Scale: $1=$ not like me at all, $2=$ a little like me, $3=$ somewhat like me, $4=$ mostly like me and $5=$ very much like me. The data of all participants were sent to VIA institute and the aggregate scores for individual strengths were requested. In the present study, the data of only humanity strength were utilized.

One week before questionnaire administration, consent forms which included the explanation of research purpose and confidentiality issues were handed out to participants in class. They were requested to discuss with parents for participation and informed that they could choose non-participation for any sort of reasons. On the day of questionnaire administration, the participants were recruited class by class and gathered in a vacant classroom of respective school. After explaining questionnaire rating formats, the questionnaire completion process was started. The whole process took approximately 45 minutes. The gathered data were coded into SPSS data file. Before hypothesis testing, exploratory factor analysis and analysis of internal consistency were executed to SOPS, so as to maximize the effectiveness of SOPS in Myanmar context. Hypotheses were answered by applying SPANOVA, standard multiple regression and MANOVA in data analysis.

\section{Data Analysis and Results}

First, exploratory factor analysis (EFA) was conducted for the relevant usage of SOPS in Myanmar context. Running EFA demands two requirements for suitability of the data: adequate sample size and the strength of interitem relationship (Pallant, 2011). Nunnally (1978) recommended the minimum value of participants-to-item ratio as 10 for running factor analysis appropriately and the ratio was $9.95(378 / 38)$ in the present study. Barlett's test of sphericity was significant $(p<0.001)$. Kaiser-Meyer-Olkin $(\mathrm{KMO})$ measure of sampling adequacy produced a value of 0.879 which was greater than 0.8 - a meritorious sampling adequacy according to Hutcheson and Sofroniou (1999). Hence, the results proved satisfactory sample size for applying EFA. Secondly, the inter-item correlation of SOPS was examined. According to Field (2013), the variables which had lots of correlations below 0.3 in correlation matrix should be removed. However, he warned about the term he used- "about 0.3 " and "lots of"- -which was not definite and clear, suggesting the readers to act according to circumstances. In the present study, the criterion of removing item was set at no correlations of above 0.25 , in order to avoid being too stringent. Every item was correlated with at least another one item above 0.25 and item deletion was not necessary.

Principal component analysis (PCA) was applied because PCA is a better method to explore "empirical summary of data set" according to Tabachnick and Fidell (2007, p. 635). Varimax rotation technique was selected because varimax is a technique of orthogonal rotation approach preferred for uncorrelated factor solutions (Field, 2013) and the two dimensions — responsiveness and control—were assumed as independent to each other. Items were extracted into two components (see Table 1 and 2). In maternal parenting, besides cross loadings (item 10, 
26 and 32 loaded on both factors), 6 items of the responsiveness dimension-10, 22, 28, 30, 32 and 34 -were loaded on control dimension. According to the rule of Tabachnick and Fidell (2007), a cross loaded item has loading value of 0.32 or higher for two or more factors. In paternal parenting, there was no cross loading but 6 items of the responsiveness dimension-22, 26, 28, 30, 32 and 34 -were loaded on control dimension. To maintain a clear factor structure, those 7 items-10, 22, 26, 28, 30, 32 and 34 -were removed. 7 items from control dimensions $(5,7,9,11,13,17$ and 29) were also removed to balance the number of items in two dimensions. Although any 7 items could be removed from control dimension, those items were selected according to the relatedness in the meaning of 7 responsiveness items. 24 items, i.e., 12 for responsiveness and 12 for control, were remained. The internal consistency was 0.759 for maternal responsiveness, 0.768 for maternal control, 0.746 for paternal responsiveness and 0.773 for paternal control; and the maximum alpha if item deletion was executed was $0.751,0.768,0.743$ and 0.767 respectively. Item deletion did not produce higher alpha than that of original 12 items. Hence, data of 24 items were used for hypothesis testing.

Table 1. Rotated Component Matrix of Maternal Parenting

\begin{tabular}{|l|c|c|l|c|c|}
\hline Items & Component 1 & Component 2 & Items & Component 1 & Component 2 \\
\hline M-17 & 0.592 & & M-33 & 0.395 & \\
\hline M-31 & 0.581 & & M-10 & 0.369 & 0.322 \\
\hline M-29 & 0.559 & & M-3 & 0.368 & \\
\hline M-23 & 0.543 & & M-15 & 0.362 & \\
\hline M-25 & 0.541 & & M-21 & 0.359 & \\
\hline M-35 & 0.535 & & M-7 & & 0.695 \\
\hline M-9 & 0.529 & & M-1 & & 0.583 \\
\hline M-32 & 0.517 & 0.333 & M-4 & & 0.578 \\
\hline M-38 & 0.513 & & M-16 & & 0.558 \\
\hline M-34 & 0.51 & & M-12 & & 0.512 \\
\hline M-19 & 0.51 & & M-14 & & 0.478 \\
\hline M-13 & 0.507 & & M-8 & 0.314 & 0.456 \\
\hline M-37 & 0.506 & & M-2 & & 0.451 \\
\hline M-30 & 0.503 & & M-36 & & 0.443 \\
\hline M-11 & 0.476 & & M-20 & & 0.414 \\
\hline M-22 & 0.457 & & M-6 & & 0.384 \\
\hline M-5 & 0.457 & & M-24 & & 0.346 \\
\hline M-27 & 0.448 & & M-28 & 0.335 & \\
\hline M-26 & 0.411 & & & & \\
\hline
\end{tabular}

First, parenting differences according to parent-child gender were examined through SPANOVA (split-plot ANOVA). The four parenting features - maternal responsiveness, maternal control, paternal responsiveness and paternal control-were treated as within-subject factors, and gender of children was treated as between-subject factor. According to Pallant (2011), sample size of above 30 enables the analysis of variance techniques to be tolerant of violation of normality assumption and the present study possessed a sample size of 378. Box's M test was significant $F(10,355917.074)=2.356, p=0.009$, indicating the violation of the assumption for equal covariance across groups. According to Tabachnick and Fidell (2007), Pillai's Trace was more robust in the presence of assumption violations, and hence, Pillai's Trace statistic was used for assessment of significant effect. The statistic showed significant main effect of parenting $F(3,374)=33.842, p<0.001$, while there was no interaction between parenting and child-gender $F(3,374)=1.725, p=0.161$. The comparison of main effect showed slightly higher maternal responsiveness and control than that of father: according to the criteria of Cohen (1988), " $d$ " value of below 0.5 reflects small effect size, and the parent-gender effect on responsiveness and control established $d_{a v}$ of 0.137 and 0.237 (see Table 3). Although the responsiveness and control of mother were higher than that of father, parental responsiveness and care were not different for boys and girls.

Second, the effect of parenting dimensions on strengths of humanity was investigated through standard multiple regression analysis because standard regression technique is useful in exploring how much variance in a dependent variable can be explained by a group of independent variables, according to Pallant (2011). Required assumptions for multiple regression analysis - sample size; mulitcollinearity and singularity; outliers; and normality, linearity, homoscedasticity and independence of residuals_—were examined first as suggested by Pallant (2011). Stevens (1996) suggested the participant-to-predictor ratio as 15 for reliable regression equation and the ratio was 25.2 in the present study. To examine the existence of multicollinearity among the parenting dimensions, bivariate correlation analysis was conducted. According to Field (2013), correlation of above 0.8 was the sign of multicollinearity and the results in Table 4 showed that the maximum amount of correlation among parenting dimensions was 0.772 . For deleting the cases with univariate outliers, the humanity strength variables were first 
examined, in order for usage of the resulted data in running MANOVA - for the effect of parenting styles on humanity strengths. 6 participants were detected to provide extreme scores, getting removed from the sample, and the data of 372 was maintained. Then, the outliers of parenting dimensions were identified and further removal was done to 5 participants, remaining the data of 367 participants.

Table 2. Rotated Component Matrix of Paternal Parenting

\begin{tabular}{|l|c|l|l|c|c|}
\hline Items & Component 1 & Component 2 & Items & Component 1 & Component 2 \\
\hline F-31 & 0.633 & & F-11 & 0.42 & \\
\hline F-17 & 0.62 & & F-21 & 0.405 & \\
\hline F-38 & 0.568 & & F-19 & 0.402 & \\
\hline F-29 & 0.558 & & F-3 & 0.384 & \\
\hline F-35 & 0.533 & & F-15 & 0.32 & \\
\hline F-37 & 0.528 & & F-7 & & 0.674 \\
\hline F-9 & 0.508 & & F-1 & & 0.593 \\
\hline F-13 & 0.508 & & F-16 & & 0.581 \\
\hline F-32 & 0.507 & & F-4 & & 0.511 \\
\hline F-30 & 0.497 & & F-14 & & 0.505 \\
\hline F-26 & 0.474 & & F-18 & & 0.485 \\
\hline F-23 & 0.474 & & F-12 & & 0.468 \\
\hline F-22 & 0.471 & & F-24 & & 0.453 \\
\hline F-28 & 0.466 & & F-6 & & 0.422 \\
\hline F-27 & 0.461 & & F-20 & & 0.421 \\
\hline F-5 & 0.449 & & F-8 & & 0.404 \\
\hline F-33 & 0.445 & & F-36 & & 0.343 \\
\hline F-25 & 0.444 & & & & \\
\hline F-34 & 0.433 & & & & \\
\hline
\end{tabular}

Finally, regression was run for initial checks. The Normal P-P Plot produced a straight line and the scatter plot demonstrated rectangularly distributed and centre-concentrated points for all regression analysis, providing evidence for normality and linearity of residuals. Regarding outliers with standardized residual value of above \pm 3.3 , there were no cases in analysis for love, only 1 case in analysis for kindness, and one case, too, in analysis for social intelligence, indicating that the percentage of residual outliers was acceptable: less than $1 \%$ of the whole sample. However, five participants had the Mahalanobis distance of above critical value (18.47) and after removing them, the data of 362 participants were kept. The maximum value of Cook's distance was $0.035,0.072$ and 0.91 , respectively for love, kindness and social intelligence: all values were lower than 1, indicating absence of cases that might influence regression model. Using the data of 362 participants, parenting dimensions were regressed on love, kindness and social intelligence separately (see Table 5). Only maternal responsiveness predicted significantly for love and social intelligence, and only paternal control had significant prediction for kindness. Holistically, the parenting dimensions explained $11.3 \%$ variance in love, $11.6 \%$ variance in kindness and $9 \%$ variance in social intelligence of children.

Table 3. Comparison of Parenting Dimensions in Terms of Parent-Gender

\begin{tabular}{|c|c|c|c|c|c|}
\hline Parenting & Gender & Mean & Mean Difference & $p$ (Bonferroni adjusted $)$ & $d_{a v}$ \\
\hline \multirow{2}{*}{ Responsiveness } & Mother & 43.38 & \multirow{2}{*}{1.084} & \multirow{2}{*}{0.006} & \multirow{2}{*}{0.137} \\
\hline & Father & 42.42 & & & \\
\hline \multirow{2}{*}{ Control } & Mother & 46.01 & \multirow{2}{*}{1.474} & \multirow{2}{*}{$<0.001$} & \multirow{2}{*}{0.237} \\
\hline & Father & 44.44 & & & \\
\hline
\end{tabular}


Table 4. Bivariate Correlation of Parenting Dimensions

\begin{tabular}{|l|c|c|c|}
\hline & Paternal Responsiveness & Maternal Control & Paternal Control \\
\hline Maternal Responsiveness & $.620^{* *}$ & $.467^{* *}$ & $.385^{* *}$ \\
\hline Paternal Responsiveness & & $.415^{* *}$ & $.464^{* *}$ \\
\hline Maternal Control & & & $.772^{* *}$ \\
\hline
\end{tabular}

** Correlation is significant at the 0.01 level (2-tailed).

Table 5. The Prediction of Parenting Dimensions on Strengths of Humanity

\begin{tabular}{|l|c|c|c|}
\hline & Love & Kindness & Social Intelligence \\
\hline Constant & 1.93 & 2.576 & 2.516 \\
\hline Maternal Responsiveness $(\beta)$ & $0.156^{*}$ & 0.073 & $0.14^{*}$ \\
\hline Paternal Responsiveness $(\beta)$ & 0.003 & 0.041 & 0.033 \\
\hline Maternal Control $(\beta)$ & 0.129 & 0.12 & 0.079 \\
\hline Paternal Control $(\beta)$ & 0.12 & $0.174^{*}$ & 0.118 \\
\hline$R^{2}$ & 0.113 & 0.116 & 0.09 \\
\hline F $(4,327)$ & 11.36 & 11.721 & 8.8 \\
\hline Sig. & $<0.001$ & $<0.001$ & $<0.001$ \\
\hline
\end{tabular}

Third, the effect of parenting styles on strengths of humanity was investigated through MANOVA, counting in the gender effect together with maternal and paternal parenting styles. Four types of parenting styles which included negligent, permissive, authoritarian and authoritative were identified according to the guideline of Gafoor and Kurukkhan (2014). For important assumption checks required for MANOVA, the procedure suggested by Pallant (2011) was followed. According to her, the number of participants in each group $-32(4 \times 4 \times 2)$ groups in the present study - must be larger than the number of dependent variables. Among 32 groups, some were found to have only 1 participant and also among 16 groups - when parenting styles of mother and father were paired-one-participant groups still appeared. Only when gender was paired with maternal parenting styles or paternal parenting styles, the minimum number of participants in groups was 55 and assumption for sample adequacy was met. Consequently, the interaction between parenting styles of mother and father was not taken into account. MANOVA was run separately for mother and father. Using Bonferroni correction, the alpha level was set at 0.025 .

As univariate outlier case was already solved in multiple regression analysis, multivariate normality was examined through Mahalanobis distance. Only one participant has the value of Mahalanobis distance (21.66) greater than critical value (16.27). Expecting the tiny effect of one participant, removing was abstained. The Pearson correlation coefficients of three humanity strength variables (see Table 6) proved the absence of multicolinearity.

Table 6. Bivariate Correlation of Humanity Strength Variables

\begin{tabular}{|l|c|c|}
\hline & Kindness & Social Intelligence \\
\hline Love & $.225^{* *}$ & $.188^{* *}$ \\
\hline Kindness & & $.262^{* *}$ \\
\hline
\end{tabular}

** Correlation is significant at the 0.01 level (2-tailed).

In MANOVA for father's parenting style effect, the test of Box's M testified to the equal covariance matrices across groups $F(42,62567.159)=1.345, p=0.067$, while the test was significant in MANOVA for mother's parenting style effect $F(42,58165.403)=1.680, p=0.004$, and hence, Pillai's Trace statistic was used in assessment of significant effect. The statistic showed significant main effect of parenting styles of both mother and father with small effect size: according to the criteria of Cohen (1988), " $\eta_{p}^{2}$ " value of 0.02 to 0.06 reflects small effect size, and value above 0.06 reflects moderate effect size (see Table 7). Gender effect did not exist for humanity strength variables, both in terms of main and interaction effect. 
Table 7. The Effect of Parenting Styles and Gender on Strength of Humanity

\begin{tabular}{|l|c|c|c|c|c|c|}
\hline Effect & Pillai's Trace & $F$ & Hypothesis $d f$ & Error $d f$ & Sig. & $\eta_{p}^{2}$ \\
\hline Maternal Parenting Styles & .158 & 6.757 & 9.000 & 1092.000 & $<0.001$ & .053 \\
\hline Paternal Parenting Styles & .860 & 6.254 & 9.000 & 881.163 & $<0.001$ & .049 \\
\hline Gender & .017 & 2.106 & 3.000 & 362.000 & .099 & .017 \\
\hline Maternal Parenting Styles * Gender & .022 & .913 & 9.000 & 1092.000 & .513 & .007 \\
\hline Paternal Parenting Styles * Gender & .972 & 1.143 & 9.000 & 881.163 & .329 & .009 \\
\hline
\end{tabular}

According to Table 8, parenting styles of both mother and father had moderate significant effect on the three strengths of humanity, except the low moderate effect of father's parenting style on love.

Table 8. The Effect of Parenting Styles on Love, Kindness and Social Intelligence

\begin{tabular}{|l|l|c|c|c|c|c|}
\hline \multirow{2}{*}{ Independent Variable } & Dependent Variable & $F$ & $\begin{array}{c}\text { Hypothesis } \\
d f\end{array}$ & Error $d f$ & Sig. & $\eta_{p}^{2}$ \\
\hline \multirow{3}{*}{ Parenting Styles of Mother } & Love & 10.227 & 3 & 364 & $<0.001$ & .078 \\
\cline { 2 - 8 } & Kindness & 9.787 & 3 & 364 & $<0.001$ & .075 \\
\cline { 2 - 8 } & Social Intelligence & 9.873 & 3 & 364 & $<0.001$ & .075 \\
\hline \multirow{3}{*}{ Parenting Styles of Father } & Love & 7.305 & 3 & 364 & $<0.001$ & .053 \\
\cline { 2 - 8 } & Kindness & 6.770 & 3 & 364 & $<0.001$ & .075 \\
\cline { 2 - 8 } & Social Intelligence & 7.801 & 3 & 364 & $<0.001$ & .071 \\
\hline
\end{tabular}

The group comparison results based on Bonferroni correction (see Table 9 and 10) revealed the negative effect of negligent parenting. In all three strengths of humanity, the children of negligent parenting established significantly lower scores than the rest parenting styles. The level of love in children of negligent mothers was lower than those of permissive and authoritative mothers. Similarly, the feeling of love in children of negligent fathers was lower than those of authoritarian and authoritative fathers. In the strength of kindness, children of authoritative parents were higher than those of negligent and permissive parents. In social intelligence, children of negligent mothers were lower than those of authoritative mother, while children of negligent fathers were lower than those of fathers who practiced the other parenting styles — authoritative, authoritarian and permissive. Table 9. Bonferoni Adjusted Pairwise Comparison for the Effect of Maternal Parenting Styles

\begin{tabular}{|l|c|c|c|c|c|}
\hline \multirow{2}{*}{ Dependent Variable } & Parenting Style of Mother & \multirow{2}{*}{ Mean Difference (I-J) } & Std. Error & Sig \\
\cline { 2 - 3 } & $(\mathrm{I})$ & $(\mathrm{J})$ & & 0.099 & 0.037 \\
\hline \multirow{2}{*}{ Love Score } & Negligent & Permissive & $-.274^{*}$ & 0.078 & $<0.001$ \\
\cline { 2 - 6 } & Negligent & Authoritative & $-.428^{*}$ & 0.063 & $<0.001$ \\
\hline Kindness & Negligent & Authoritative & $-.339^{*}$ & 0.082 & 0.028 \\
\cline { 2 - 6 } & Permissive & Authoritative & $-.234^{*}$ & 0.07 & $<0.001$ \\
\hline
\end{tabular}

Table 10. Bonferoni Adjusted Pairwise Comparison for the Effect of Paternal Parenting Styles

\begin{tabular}{|l|l|l|l|l|l|}
\hline \multirow{2}{*}{ Dependent Variable } & Parenting Style of Father & Mean Difference (I-J) & Std. Error & \multirow{2}{*}{ Sig } \\
\cline { 2 - 6 } & $(\mathrm{I})$ & $(\mathrm{J})$ & & \\
\hline \multirow{3}{*}{ Love Score } & Negligent & Authoritarian & $-.264^{*}$ & 0.097 & 0.042 \\
\cline { 2 - 6 } & Negligent & Authoritative & $-.344^{*}$ & 0.079 & $<0.001$ \\
\hline \multirow{3}{*}{ Kindness } & Negligent & Authoritative & $-.332^{*}$ & 0.063 & $<0.001$ \\
\cline { 2 - 6 } & Permissive & Authoritative & $-.249^{*}$ & 0.08 & 0.012 \\
\hline & Negligent & Authoritarian & $-.250^{*}$ & 0.086 & 0.022 \\
\cline { 2 - 6 } & Negligent & Permissive & $-.241^{*}$ & 0.087 & 0.034 \\
\cline { 2 - 6 } & Negligent & Authoritative & $-.357^{*}$ & 0.07 & $<0.001$ \\
\hline
\end{tabular}

\section{Discussion and Conclusion}

The main purpose of this study was to explore whether the merit of authoritative parenting styles could be found in Myanmar, an Asian society, using strengths of humanity as indicator which would reflect the merit. Specifically, the present study investigated the effect of parent-child gender type on parenting; the effects of parenting 
dimensions (parental responsiveness and parental control) on the strengths of humanity; and the effect of parenting styles on the strengths of humanity.

First, the parenting differences in terms of parent-child gender were explored and it was found that Myanmar adolescents perceived their mothers as more responsive and more controlling to them than their fathers. The result supported the finding of Shek (2000): fathers were perceived as less responsive and less demanding, and the result was also indirectly in line with the proposition of Patterson (1982) about mother's more engagement in disciplinary actions in that disciplining also includes control and demands. However, perception with parental responsiveness and control was not different between boys and girls. The result was contradicted with the findings of many studies which proved more control of fathers on son (Xie, 1998; Trommsdorff and Iwawaki, 1989; Rohner \& Pettengill, 1985 ) and with the claims of Leaper (2002) about more maternal responsiveness to girls.

Then, to answer Hypothesis No (1) and (2), the maternal responsiveness, maternal control, paternal responsiveness and paternal control were regressed on strengths of humanity. Only maternal responsiveness predicted love and kindness, while social intelligence was positively predicted only by paternal control. Regardless of significance, all parenting dimensions showed positive relations with strengths of humanity. Hence, the proposition of Hypothesis No.2 was nullified. Hypothesis No.1 cannot be fully verified, too. The positive effect of maternal responsiveness on love and kindness strengths of adolescents supported the finding of Ngai (2015): parental care positively predicted integrity, bravery, persistence, kindness, love, social intelligence, fairness and self-regulation. On the contrary, the positive effect of paternal control on social intelligence of adolescents was against the results that Ngai (2015) obtained - the negative effect of parental control on eight character strengths. The present study found that both parenting dimensions were positively related to strengths of humanity.

Finally, the effect of four parenting styles (negligent, authoritarian, permissive and authoritative) on strengths of humanity was investigated and the results proved Hypothesis No.3. Adolescents of authoritative mothers possessed higher strengths of humanity than those of negligent mothers; and higher kindness than those of permissive mothers. Similar result was found with authoritative fathers. Adolescents of authoritative fathers showed higher strengths of humanity than those of negligent fathers; and higher kindness than those of permissive fathers. Adolescents of negligent mothers also had lower level of love than those of permissive mothers, while adolescents of negligent fathers revealed lower level of love than those of authoritarian fathers. In social intelligence, adolescents of negligent father were lower than their counterparts of parents who practiced authoritative, authoritarian and permissive styles. All in all, authoritative parenting style was better than the rest styles; negligent style was the worst; while permissive and authoritarian styles did not show significant differences for the strengths of humanity. The results were in line with what Darling (1999) claimed about the consequences of parenting styles: children and adolescents of authoritative parents performed better than non-authoritative parents in the domains of social competence, academic achievement, psychosocial development, and involvement in problematic behaviour, while those of negligent parents showed poorest performance in all domains. The results also proved the benefit of authoritative parenting styles in an Asian society.

On the contrary of the gender difference in character strengths found by Park and Peterson (2006) and Shimai, Otake, Park, Peterson and Seligman (2006), i.e., females tended to report strengths of love and kindness more than males, no gender effect on strengths of humanity was found in the present study. Gender produced no interaction effect with parenting and also it was already described above that gender effect did not exist for adolescents' perception with parental responsiveness and control. The reason of non-significant gender effect might be the big gap between the number of male and female participants. Male comprised only $35.4 \%$ of the sample. To be concluded, the present study proved that both of parental responsiveness and parental control, as well as their combined effect (parenting styles of both parents) played an important role in the development of strengths of humanity.

\section{Limitation and Recommendation for Future Research}

The first limitation of this study was convenient sampling. Participants were recruited from secondary schools for the sake of convenience, and the generalizability of findings would exclude Myanmar adolescents who were not students. The second limitation was application of only one type of reporters: the adolescents. Leung, Daniel and Shek (2014) revealed the negative effect of "the discrepancies in perception of parents and adolescents with parenting characteristics" on developmental outcomes of adolescents. Measuring parenting practices from the perception of both parents and children would help the future researchers to pursue more extensive understanding on the relations of parenting and outcome variables. The third limitation was cross-sectional design of the study. The onset of parenting process comes right after the birth of a person and parenting characteristic changes across the developmental stage of the offspring. Longitudinal studies could provide more comprehensive findings with the effect of parenting.

\section{References}

Baldwin, A. L. (1955). Behavior and development in childhood. New York: Dryden Press. 
Baumrind, D. (1968). Authoritarian vs. authoritative parental control. Adolescence, 3, 255-272.

Baumrind, D. (1991). The influence of parenting style on adolescent competence and substance use. Journal of Early Adolescence, 11(1), 56-95.

Buri, J. R. (1991). Parental Authority Questionnaire. Journal of Personality Assessment, 57, 110-119.

Champney, H. (1941). The measurement of parent behavior. Child Development, 12, 131-166.

Chao, R. (2001). Extending research on the consequences of parenting style for Chinese Americans and European Americans. Child Development, 72, 1832-1843.

Chao, R., \& Tseng, V. (2002). Parenting of Asians. In M. H. Bornstein (Series ed.), Handbook of parenting: Vol. 4, Social conditions and applied parenting (2nd ed., pp. 59-93). Mahwah, New Jersey: Lawrence Erlbaum Associates.

Cohen, J. W. (1988). Statistical power analysis for the behavioral sciences (2nd ed). Hillsdale, NJ: Lawrence Erlbaum Associates.

Darling, N. (1999). Parenting style and its correlates. ERIC Digest, 1-7.

Dornbusch, S. M., Ritter, P. L., Leiderman, H. P., Roberts, D. F, \& Fraleigh, M. J. (1987). The relation of parenting style to adolescent school performance. Child Development, 58, 1244-1257.

Field, A. (2013). Discovering statistics using IBM SPSS statistics ( $4^{\text {th }}$ ed). London: Sage publications.

Gafoor, K. A., \& Kurukkan, A. (2014). Construction and validation of scale of parenting style. Guru Journal of Behavioral and Social Sciences, 2(4), 315-323.

Hutcheson, G., \& Sofroniou, N. (1999). The multivariate social scientist. London: Sage.

Leaper, C. (2002). Parenting girls and boys. In M. H. Bornstein (Series ed.), Handbook of parenting: Vol. 1, Children and Parenting (2nd ed., pp. 189-225). Mahwah, New Jersey: Lawrence Erlbaum Associates.

Leung, K., Lau, S., \& Lam, W. L. (1998). Parenting styles and achievement: A cross-cultural study. MerrillPalmer Quarterly, 44, 157-172.

Leung, J. T. Y., \& Daniel T. L. Shek, D. T. L. (2014). Parent-adolescent discrepancies in perceived parenting characteristics and adolescent developmental outcomes in poor Chinese families. J Child Fam Stud, 23, 200213. DOI 10.1007/s10826-013-9775-5

Lorr, M. G., \& Jenkins, R. L. (1953). Three factors in parent behavior. Journal of Consulting Psychology, 17, 306308.

Maccoby, E. E., \& Martin, J. A. (1983). Socialization in the context of the family: Parent-child interaction. In P. Mussen, \& E. M. Hetherington (Eds.), Handbook of Child Psychology: Socialization, personality, and social development (Vol. 4). New York: Wiley.

McBride-Chang, C., \& Chang, L. (1998). Adolescent-parent relations in Hong Kong: Parenting styles, emotional autonomy, and school achievement. Journal of Genetic Psychology, 159, 421-436.

Miller, N. B., Cowan, P. A., Cowan, C. P., \& Hetherington, E. M. (1993). Externalizing in preschoolers and early adolescents: A cross-study replication of a family model. Developmental Psychology, 29(1), 3-18.

Moua, S. (2010). Parenting Styles of Hmong Parents and its Effects and Contributions to Hmong Student's Academic Achievement. A Research Paper Submitted in Partial Fulfillment of the Requirements for the Master of Science Degree, School Counseling, University of Wisconsin-Stout.

Ngai, S. S. (2015). Parental bonding and character strengths among Chinese adolescents in Hong Kong. International Journal of Adolescence and Youth, 20(3), 317-333, DOI: 10.1080/02673843.2015.1007879

Niemiec, R. M. (2013). VIA character strengths: Research and practice (The first 10 years). In H. H. Knoop \& A. Delle Fave (Eds.), Well-being and cultures: Perspectives on positive psychology (pp. 11-30). New York: Springer.

Nunnally, J. O. (1978). Psychometric theory. New York: McGraw-Hill.

Pallant, J. (2011). SPSS survival manual: A step by step guide to data analysis using the SPSS Program (4 ${ }^{\text {th }}$ ed). Allen \& Unwin: Berkshire.

Park, N. (2004). Character strengths and positive youth development. The Annals of the American Academy of Political and Social Science, 591, 40-54.

Park, N. (2009). Building strengths of character: Keys to positive youth development. Reclaiming Children and Youth, 18(2) 42-47.

Park, N., \& Peterson, C. (2006). Moral competence and character strengths among adolescents: The development and validation of the Values in Action Inventory of Strengths for Youth. Journal of Adolescence, 29, 891905.

Patterson, G. R. (1982). Coercive family process. Eugene, OR: Castlia Press.

Peterson, C., \& Seligman, M. E. P. (2004). Character strengths and virtues: A handbook and classification. New York, NY: Oxford University Press.

Roe, A., \& Siegelman, M. (1963). A parent-child relations questionnaire. Child Development, 34(2), $355-369$.

Rohner, R. P. (1976). They love me, they love me not: A worldwide study of the effects of parental acceptance and rejection. New Haven, CT: Yale University Press. 
Rohner, R. P., \& Pettengill, S. M. (1985). Perceived parental acceptance-rejection and parental control among Korean adolescents. Child Development, 56, 524-528.

Ruch, W., Martínez-Martí, M. L., Proyer, R. T., \& Harzer, C. (2014). The Character Strengths Rating Form (CSRF): Development and initial assessment of a 24 -item rating scale to assess character strengths. Personality and Individual Differences, 68, 53-58.

Schaefer, E. S. (1959). A circumplex model for maternal behavior. Journal of Abnormal and Social Psychology, 59, 226-235.

Sessa, F. M., Avenevoli, S., Steinberg, L., \& Morris, A. S. (2001). Correspondence among informants on parenting: Preschool children, mothers, and observers. Journal of Family Psychology, 15, 53-68.

Shek, D. (2000). Differences between fathers and mothers in the treatment of, and relationship with, their teenage children: Perception of Chinese adolescents. Adolescence, 35, 135-146.

Shimai, S., K. Otake, K., Park, N., Peterson, C., \& Seligman, M. E. P. (2006). Convergence of character strengths in american and japanese young adults. Journal of Happiness Studies, 7(3), 311-322.

Slater, P. E. (1962). Parental behavior and the personality of the child. Journal of Genetic Psychology, 101, 5368.

Steinberg, L., Dornbusch, S.M., \& Brown, B.B. (1992). Ethnic differences in adolescent achievement: An ecological perspective. American Psychologist, 47, 723-729.

Stevens, J. (1996). Applied multivariate statistics for the social sciences ( $\left.3^{\text {rd }} \mathrm{ed}\right)$. Mahwah, NJ: Lawrence Erlbaum.

Tabachnick, B.G., \& Fidell, L.S. (2007). Using Multivariate Statistics (5 ${ }^{\text {th }}$ ed.). New York: Allyn and Bacon.

Trommsdorff, G., and Iwawaki, S. (1989). Students' perceptions of socialization and gender role in Japan and Germany. International Journal of Behavioral Development, 12, 485-493.

Wagner, L., \& Ruch, W. (2015). Good character at school: Positive classroom behavior mediates the link between character strengths and school achievement. Frontiers in Psychology, 6(24). DOI: 10.3389/fpsyg.2015.00610

Weiss, L. H., \& Schwarz, J. C. (1996). The relationship between parenting types and older adolescents' personality, academic achievement, adjustment, and substance use. Child Development, 67(5), 2101-2114.

Xie, Q. (1998). Perceptions of childrearing practices by Chinese parents and their only children, and their relations to children's school achievement. Dissertation Abstracts International, 58, 3425.

\section{Appendix}

1. My mother/father does whatever I tell.

2. My mother/father spends free time with me.

3. My mother/father points out my mistakes in the manner that I understand.

4. My mother/father gives money for my needs.

5. My mother/father discusses the benefits and detriments of my learning topics.

6. My mother/father considers my likes in food.

7. My mother/father controls my game when in excess.

8. My mother/father shows love to me.

9. My mother/father enquires the reason for my failure.

10. My mother/father helps me in studying.

11. My mother/father confers responsibilities in accordance with my growth.

12. My mother/father has faith in me

13. My mother/father enquires the reasons for reaching home late

14. My mother/father accepts my privacy

15. My mother/father takes care of my dressing

16. My mother/father fulfils my desires with available means.

17. My mother/father makes me aware that the responsibility of what $\mathrm{i}$ do is mine itself.

18. My mother/father accepts when i say no to what i dislike.

19. My mother/father tells how i should behave with their friends.

20. My mother/father talks to me praising about their friends.

21. My mother/father tries to frame my likes and dislikes.

22. My mother/father appreciates when i try to become independent.

23. My mother/father punishes for my mistakes.

24. My mother/father shows love when i do any mistake.

25. My mother/father enquires who my friends are.

26. My mother/father has given me freedom to select the subject for study.

27. My mother/father organizes time for my play.

28. My mother/father gives priorities to my preferences in studies.

29. My mother/father demands me to be systematic in studies.

30. My mother/father emphasizes my successes. 
31. My mother/father advices me.

32. My mother/father celebrates in my successes with me.

33. My mother/father discourages unhealthy foods.

34. My mother/father gets anxious when i am late to reach home.

35. My mother/father inquires how i spend money.

36. My mother/father buy dresses for me according to the latest trends.

37. My mother/father enquires how i spend my free time.

38. My mother/father gives me timely advices. 